\title{
How Does Human Capital Matter? Evidence from Venture Capital *
}

\author{
Lifeng Gu, ${ }^{\dagger}$ Ruidi Huang, ${ }^{\ddagger}$ Yifei Mao, ${ }^{\S}$ and Xuan Tian $₫$
}

December 2017

\begin{abstract}
We investigate the effects of human capital mobility on venture capital (VC) investment and outcomes. To establish causality, we use a difference-in-differences approach that relies on plausibly exogenous variations generated by states' staggered recognition of the inevitable disclosure doctrine (IDD). We find that a reduction in human capital mobility reduces VCs' investment propensity and successful exit. Further analysis shows that the effects are more pronounced in industries with more high-skilled worker$\mathrm{s}$, in industries with higher patenting intensity, and in earlier-stage VC investment. To mitigate the adverse effect of the IDD, VCs stage finance startups more and are more likely to syndicate with other VCs. Finally, we show that the IDD reduces the mobility of inventors, which contributes to a reduction in startups' patenting and successful exit. Our paper sheds new light on the effects of an important but underexplored determinant of VC investment - the human capital of startups.
\end{abstract}

JEL Classifications: G24, G23, G34.

Keywords: Venture capital, inevitable disclosure doctrine, human capital risk.

${ }^{*}$ We thank Michael S. Weisbach and Joe Zhou for helpful comments. We remain responsible for any errors and omissions.

${ }^{\dagger}$ University of Hong Kong, email: oliviagu@hku.hk.

${ }^{\ddagger}$ University of Illinois at Urbana-Champaign, email: rhuang12@illinois.edu.

${ }^{\S}$ Cornell University, email: ym355@cornell.edu.

ฯTsinghua University, email: tianx@pbcsf.tsinghua.edu.cn. 


\section{Introduction}

How does the human capital of startup companies affect the investment propensity and outcomes of venture capitalists (VCs)? This is an important research question because capital formation starts with the private market, which has contributed significantly to the rapid development of U.S. economic growth, entrepreneurship, and technological innovation in the past several decades. VCs have been an important ingredient of the private market. For example, $60 \%$ of IPOs have been VC-backed since 1999. Although numerous studies have explored how a variety of VC investors' characteristics (e.g., industry expertise, reputation, experience, network connections) affect their investment in startup companies, no previous research has focused on the effects of human capital embedded in startup companies on VC investment. Studies that have explored other aspects of startup companies' human capital are Hellmann and Puri (2000) and Chemmanur et al. (2014). In their study of 170 hightech startups in Silicon Valley, Hellmann and Puri (2000) find that VCs help professionalize startup management teams. Chemmanur et al. (2014) show that VC financing is associated with higher-quality startup management teams. These studies, however, do not explore how VC investment is influenced by startup human capital. In this paper, we fill this gap in the

existing literature and explore how human capital - more specifically, the mobility of human capital, affects VC investment.

A major challenge facing the empirical analysis is that human capital mobility is likely endogenous to VC investment. Thus, a correlation between human capital mobility and VC investment may tell us little about the causal effect of human capital mobility on VC investment. We alleviate endogeneity concerns by exploiting the staggered adoption of the inevitable disclosure doctrine (IDD) by U.S. state courts; this doctrine prevents a firm's employees who have knowledge of the firm's trade secrets from working for another firm, and hence creates plausibly exogenous variations in human capital mobility. A key advantage of using variation generated by the IDD is that it represents multiple shocks that affect human 
capital mobility in different states (and hence startups) at exogenously different times. We thus avoid a common identification difficulty of studies that use a single shock-namely, the existence of potential omitted variables coinciding with a shock that directly affects VC investment. We provide a detailed discussion of the institutional background of the IDD in Section 2.

We propose two competing hypotheses regarding how human capital mobility could affect VC investment and outcomes. Our first hypothesis, the Talent Retention Hypothesis, argues that startups' human capital mobility restrictions could encourage VC investment and increase their successful exit from the startups they have funded. In comparison with established companies, startups usually are in a disadvantageous position in terms of attracting and keeping talent. This is because, unlike established companies, startups usually cannot provide their employees with a stable income or a clear career path. Established companies also have a strong incentive to acquire talent through mergers and acquisitions (M\&As) (Ouimet and Zarutskie, 2016), and startup companies are typically easy targets. Therefore startup companies risk losing their key talent to established companies and competitors. When a state adopts the IDD, it becomes potentially more costly for key employees to move to competing firms (especially those who possess knowledge about core technologies), and hence it is easier for startup companies to retain their talent and VCs should be more willing to invest in these startup companies. When key talent is retained by the startups, VCs are more likely to exit successfully.

The second hypothesis predicts the opposite: that startups' human capital mobility restrictions could impede VC investment and reduce successful exits. While lower human capital mobility allows the startup companies to retain talent, it also makes it more difficult for the startup companies to recruit necessary talent from outside (see, e.g., Amornsiripanitch et al., 2016; Ewens and Marx, 2015). In particular, lower human capital mobility could distort the allocation of human capital across startup companies and increase the startup companies' human capital risk. As a result, VCs may be less willing to invest in startup 
companies when outside talent is hard to attract. Also, because the restrictions of human capital mobility lower startup companies' efficiency and productivity, VCs are less likely to exit successfully. We call this argument the Human Capital Risk Hypothesis.

We test these two competing hypotheses by examining the effects of human capital mobility restrictions on VC investment and outcomes. To address the endogeneity concern, we employ a difference-in-differences (DID) approach, taking advantage of the staggered recognition of the IDD. Our main results show that, following the adoption of the IDD, there is a 3 percentage point drop in both the likelihood of VC investment and their successful exit. The economic magnitude is sizable: the IDD reduces both VC investment likelihood and successful exit probability by approximately 25\%. The evidence appears to be consistent with the Human Capital Risk Hypothesis.

Although states' staggered adoption of the IDD produces exogenous changes to human capital mobility, it is likely that state-level factors affect the timing of the IDD in different states. If this is true, it is possible that our results are driven by reverse causality. To address this concern, we follow Bertrand and Mullainathan (2003) to examine the dynamics of VC investments surrounding the adoption and rejection of the IDD. We find no prior trend in VC investment in the pre-IDD era, and the results become significant only after the IDD adoption. These findings suggest that reverse causality does not explain our main results.

We next conduct cross-sectional tests to explore plausible channels through which the restriction of human capital mobility affects $\mathrm{VC}$ investment and outcomes. We find that the baseline results are more pronounced in industries with more high-skilled workers or higher patenting intensity, and in earlier-stage VC investment. Since startup companies with these characteristics tend to rely more on human capital (as opposed to physical capital) to survive and the restrictions of human capital mobility are associated with increased human capital risk, it appears that human capital risk is a plausible underlying mechanism through which human capital mobility affects VC investment and outcomes. 
Furthermore, we explore how VCs respond to increased human capital risk created by the IDD. We find that VCs alter their investment strategy in startup companies to mitigate the negative effect of the IDD on human capital risk. We focus on two aspects of VC investment strategy: staging and syndication. Staging is the stepwise investment from VCs in startup companies and has been well documented as an effective way to mitigate agency problems (Gompers, 1995; Tian, 2011). According to the real option theory, VCs stage their financing of startup companies to reduce investment uncertainty (Gompers, 1992; Sahlman, 1988, 1990); it is an effective tool to mitigate agency problems and keep entrepreneurs on a tight leash (Sahlman, 1990; Gompers, 1995). Syndication refers to cooperation among VCs when they invest in startup companies, and it is an enduring and distinct feature of the VC industry (Lerner, 1994; Tian, 2012). Syndication allows VCs to seek a second opinion from other VCs about the startup companies and share the risk, especially human capital risk, associated with startup companies (e.g., Brander et al., 2002; Lerner, 1994). Therefore, when human capital risk rises due to the adoptions of the IDD, VCs attempt to mitigate the adverse effect by intensifying staging and engaging in syndication. Consistent with our conjecture, we show that VCs increase the number of financing rounds and co-invest with a larger number of VCs in startup companies after the adoption of the IDD.

In the final part of the paper, we attempt to open the black-box to directly examine inventor mobility and the productivity of startup companies after IDD adoption. This analysis helps explain why restrictions on human capital mobility reduce the rate of successful VC exit. We find that, following IDD adoption, there is a significant reduction in the mobility of a key part of startup companies' talent-i.e., employees whose inventions lead to patents. In addition, startup companies' innovation quantity and quality drop: they file fewer patent applications, and each granted patent on average receives fewer future citations. This observation suggests that reduced inventor mobility due to the IDD leads to a distortion in human capital allocation across startup companies, which reduces firms' productivity and innovative output. 
Our paper contributes to three strands of the literature. First, it makes a contribution to the literature on VC investment. Prior research has studied how a variety of VC investors' characteristics, such as their industry expertise, reputation, past experience, and network connections, affect their investment in startup companies and eventually the public market (see Da Rin et al. (2013) for a survey of the literature). However, the existing literature has ignored how an important characteristic of startup companies - i.e., human capital - affects companies affects VC investment and outcomes. Our study fills this gap and explores how human capital mobility affects VCs' deal formation and investment outcomes.

Second, our study speaks to the broader literature on human capital and the firm. There is a longstanding debate on the importance of human capital in a firm. While in the HartMoore framework, nonhuman assets are the glue that holds a firm together (Hart, 1995). Zingales (2000) has stressed the increasing importance of human capital in today's world. Our paper formally establishes an important link between human capital and firms by exploring shocks to human capital mobility.

Finally, this paper is related to the emerging literature on labor mobility and economic dynamism. Klasa et al. (2017) document the impact of the inevitable disclosure doctrine on firms' capital structure choices, showing that firms increase their financial leverage following a state's adoption of the IDD, which brings more protection for firms' trade secrets. Jeffers (2017) shows that labor mobility restrictions reduce capital investment by established companies and deter new entrepreneurship. Chen et al. (2017) find that, where human capital mobility is restricted, U.S. firms are more likely to be acquired. Our paper contributes to this group of studies by showing the impact of human capital mobility in a $\mathrm{VC}$ setting.

The rest of the paper proceeds as follows: Section 2 describes the institutional background of the IDD. Section 3 reports data and summary statistics. Section 4 presents the main empirical results at the VC level. Section 5 studies productivity and human capital mobility directly. Section 6 concludes. 


\section{Trade Secrets and the Inevitable Disclosure Doctrine}

The inevitable disclosure doctrine (IDD) was first recognized by the state of New York in 1919 to protect trade secrets. In the original New York State court ruling, a trade secret is defined as any business information that can generate economic value if disclosed or used by companies' employees. The court also ruled that a trade secret is subject to reasonable protections by the company as business secret. The recognition of the IDD by state courts reinforces protection of trade secrets for firms located in those states. According to the IDD rulings, a firm can file a lawsuit against a firms that has hired a former employee if the firm can provide evidence that (1) the employee had access to its trade secrets, (2) the employee's new duties in the new employment would inevitably require her to disclose or use the trade secrets, and (3) the disclosure or use of the trade secrets would cause irreparable economic harm to the suing firm. Furthermore, the IDD protects the firm's trade secrets even if the employee is hired by a firm which is located in a state that has not adopted the IDD. The IDD maintains that if the new employment would inevitably lead to the disclosure of the trade secret to competitors and cause irreparable harm to the suing firm, a state court can prevent the employee from moving to the competitor or limit her responsibility in the new job. ${ }^{1}$

The IDD rulings reduce the risk that an employee will disclose a business secret to a competitor or take advantage of her knowledge of trade secrets to start a new company in a similar industry. Before an employee decides to move to a new company or start her own company, she must consider whether she will be breaking any regulations related to the IDD. In turn, an employee has less incentive to switch jobs if doing so could lead to a lengthy lawsuit filed by a prior employer that operates in a state that has adopted the IDD.

\section{[Insert Table 1 Here]}

\footnotetext{
${ }^{1}$ Refer to Klasa et al. (2017) for detailed discussions about the IDD rulings.
} 
For our analysis, we start with all court rulings on the IDD. If a state court ruled in favor of the IDD, we categorize this state as one that has adopted the IDD from the time of the court ruling. If a court in such a state ruled against the IDD in a later case, we define this state as one that has rejected the IDD from the date of the subsequent ruling. For example, a Texas court ruled in favor of the IDD on May 28, 1993. However, on April 3, 2003, another Texas court decided against the IDD. Such occurrences are fairly rare, with only three instances so far. The states of Florida, Michigan, and Texas rejected the previously adopted IDD several years after its initial adoption. Table 1 shows the adoption and rejection dates of the IDD in twenty-one U.S. states. The earliest adoption year was 1919 by the state of New York, and the most recent was Kansas in 2006. Klasa et al. (2017) provide details about the precedent-setting legal cases in which state courts adopted the IDD or rejected it after adoption.

The IDD rulings are of particular relevance in the VC setting because they have an important impact on young startup companies. In startups' early years, they have difficulty providing competitive compensation packages that are comparable to those of their established counterparts. But employees who work in startups are usually passionate about the firms and hope for a big payout later down the road when the venture succeeds, though it is well known that the odds are long. A promising career path ahead is rarely seen in startup companies, and startup employees are often absorbed by more mature firms when the startup is acquired. Also, with so much uncertainty in the startups, they are more likely to lose key employees to their competitors.

In the states that have adopted the IDD, however, employees find it more difficult to move, making it easier for the startups to retain talent. However, although the adoption of the IDD makes it hard for startups' employees to leave from a more established firm, it also hampers startups' ability to attract talent from outside. Thus the adoption of the IDD leads to a decline in the mobility of human capital, which is key for startup companies' success. The suboptimal human capital allocation caused by the decline in mobility leads greater concern 
among VCs about the human capital risks associated with investing in startup companies. Therefore the adoptions and rejections of the IDD provide us a good opportunity to examine the important role that startup companies' human capital mobility plays in various aspects of VC financing.

Furthermore, the staggered adoption and rejection of the IDD in the states provides us with an ideal empirical setting from which to draw causal inferences in the spirit of Bertrand and Mullainathan (2003). States become part of the treated group once they adopt the IDD. The states that have not yet passed the IDD, that have rejected the IDD, or have never tried IDD cases are in the control group. However, our control group is not restricted to states that have never passed the IDD. Our identification strategy implicitly takes as the control group all firms in states that had not yet adopted the IDD, even if they did so later on. We are essentially carrying out a difference-in-differences estimation by exploiting the staggered passage of the IDD.

\section{Data and Variables}

Our main data come from the Thomson Reuters VentureXerpt database. We include all ventures located in the United States that received their first-round funding between 1980 and 2012. We require the ventures to have complete financing information. We exclude ventures in the utilities (two-digit SIC code 49) and financial services (two-digit SIC code between 60 and 69) industries to avoid potential confounding effects from deregulation in those industries during the same time period.

\section{[Insert Table 2 Here]}

Table 2 presents variable definitions and summary statistics of all independent and dependent variables used in our tests. The top panel provides descriptions of all the variables. Investment is a dummy variable that equals one if the VC-firm deal actually takes place and 
zero otherwise. IDD is a dummy variable that equals one if the state passes the IDD and zero otherwise. VC market share is the VC's market share in the MSA where it resides at the time of investment. VC reputation is the VC's cumulative IPO market share. Firm age represents the number of years since the inception of the venture. Early dummy equals one if the firm is in the "startup/seed" or "early stage" as indicated by the VentureXerpt database and zero otherwise. Distance is the natural logarithm of the distance between the startup company and the VC. Industry fit is the percentage of deals made by the VCs in the same industry as its portfolio firm. Success is a dummy variable that equals one if the firm exits through either IPO or M\&A and zero otherwise. IPO dummy equals one if the venture goes public and zero otherwise. Acquisition dummy equals one if the startup company is acquired and zero otherwise. Deal value/amount invested is the M\&A deal value scaled by the total amount invested by VCs. Number of rounds is the total rounds of financing in each venture. Number of VCs is the total number of VCs involved in each deal. Skewness is the fraction of first-round investment over total investment in the same underlying venture. Number of patents is the total number of patents produced by the startup company until exit. Citation is the total number of citations received by the firm's patents filed before exit.

The bottom panel presents the summary statistics of these variables. We report the mean, the standard deviation, the 25th percentile, the median, and the 75 th percentile for each variable. The panel shows that a startup's probability of receiving VC financing is $12.8 \%$; an average startup company in the sample is about 4.6 years old, with $69.4 \%$ in the early stage; $61.9 \%$ of the firms exit either through an IPO (13.2\%) or M\&A (48.7\%); the average firm is invested in by 11.5 VCs in 3.9 financing rounds; the average firm generates 1.5 patents, which are cited about 2.5 times. 


\section{IDD and VC Investment}

In this section, we examine how the IDD affects the VCs' investment likelihood, successful exit probability, and investment strategy. The court rulings on the IDD often come as a surprise, and represent plausibly exogenous shocks to human capital mobility. Different states adopt and reject the IDD on different dates. We implement a difference-in-differences approach where the staggered recognition of the IDD provides us with both the control and treatment groups (e.g., Bertrand and Mullainathan, 2003). We first study the effect of the adoption and rejection of the IDD on the investment likelihood of VCs and the outcome of startup companies. We then analyze which mechanisms produced our findings by using the rich cross-sectional features of our data. We conclude this section with an examination of the impact of the adoption of the IDD on VCs' investment structure.

\subsection{Investment likelihood}

We developed two hypotheses regarding the relation between human capital mobility and the likelihood of VC investment. On the one hand, the IDD ties startups' human capital to the incumbent firm by preventing employees from moving to a competing firm. These circumstances could encourage VCs to invest. Established companies usually have an advantage over startups in attracting and keeping key employees because it is difficult for startups to provide their employees with comparable compensation packages and clear career paths. As shown by Ouimet and Zarutskie (2016), startup companies are often targeted by mature firms in M\&A wars. Startup firms constantly risk losing key employees to their competitors. But the adoption of the IDD makes it more risky for startup employees who possess knowledge about their firms' core technologies to accept employment from a competitor. When startup companies can retain their talent, VCs who value human capital are more likely to invest in these firms after the adoption of the IDD. 
On the other hand, while the IDD lowers the startups' risk of losing key talent, it also makes it more difficult for them to recruit fresh talent that could help the firms grow and succeed (Amornsiripanitch et al., 2016; Ewens and Marx, 2015). In particular, lower human capital mobility could distort the allocation of human capital across startup rms and increase the startup companies' human capital risk. As a result, VCs may be less willing to invest in startup companies when human capital is perceived to be scarce.

To formally test our hypotheses, we first investigate the likelihood of VC investment in a startup company. To do this, we construct a hypothetical sample of potential deals in the spirit of Bottazzi et al. (2016) and Gompers et al. (2016). Specifically, for every deal in our sample, we create hypothetical VC-startup pairs. We posit that it is possible for every VC firm to fund each startup company if it chooses to do so. For example, when VC A invests in one firm, $\mathrm{VC} \mathrm{B}$ could also have considered investing. $\mathrm{VC} \mathrm{B}$ could even join the action if it desires. Ideally, we would collect data about whether each VC considered each startup. However, such data are costly and almost impossible to obtain. Creating this hypothetical sample allows us to simulate the data to study the likelihood of $\mathrm{VC}$ investment.

We create this hypothetical sample with two restrictions in mind. First, we require that the VCs exist before the startup companies are founded. Second, we restrict the sample to VCs who have invested in at least one deal in the same industry as the startups over the next thirty days. This restriction allows us to better capture the true investment intention of the VCs. ${ }^{2}$ We end up with 374,180 potential deals. Then we estimate the VCs' investment decisions with the following specification:

$$
I N V E S T_{p}=\beta I D D+\gamma^{\prime} X+\theta^{\prime} Y+\lambda^{\prime} Z+\tau_{t}+\alpha_{k}+\delta_{j}+\epsilon_{p},
$$

where $p$ indexes potential investor-firm pairs. The dependent variable is INVEST, which is a dummy variable that represents whether an investor finances a startup firm. IDD is a

\footnotetext{
${ }^{2}$ We eliminate the same-industry requirement and extend the window to 90 days in robustness tests. We find qualitatively similar results.
} 
dummy variable that equals one if firm $i$ in state $j$ has adopted the IDD by year $t$ and zero otherwise. If state $j$ subsequently rejected the IDD at year $t+n$, then we assign zeros to $I D D$ for firm $i$ in state $j$ for the years after the rejection. $X$ represents firm-level variables to account for observable characteristics of different ventures. $Y$ represents VC-level controls. $Z$ represents variables that vary at the investor-firm pair level. Specifically, $X$ includes Ln(age) and Early dummy, $Y$ includes $V C$ market share and $V C$ reputation, $Z$ includes Distance and Industry fit. These variables are frequently used in the VC literature and potentially influence the likelihood of VC investment. Moreover, we include various fixed effects. $\tau_{t}, \alpha_{k}$, and $\delta_{j}$ represent year, industry, and MSA fixed effects, respectively. They control for observable as well as unobservable time trends, industry factors, and MSA-specific characteristics, respectively. $\beta$ is our coefficient of interest, and it captures the effect of the IDD rulings on VCs' investment decisions.

\section{[Insert Table 3 Here]}

We estimate Equation (1) using a linear probability model and present the baseline results in Table 3. Columns (1), (2), and (3) report the estimation results for three different specifications. $^{3}$ All three columns show a negative and statistically significant coefficient on the IDD dummy. Taking Column (3) as an example, the regression coefficient on the IDD dummy is $-3.24 \%$, which is statistically significant at the $1 \%$ level. This result is also economically sizable. Given that the unconditional probability of VCs' investing in the startup companies is around $12.8 \%$, our findings represent a $25 \%$ drop in the likelihood of VC investment in a startup after the adoption of the IDD. Together our results suggest that, after the adoption of the IDD, VCs' investment likelihood decreases significantly. In other words, startup companies are less likely to receive VC financing after the adoption of the IDD. This is consistent with our hypothesis that investors are concerned about the human capital risk associated with the IDD and hence adopt a more conservative investment

\footnotetext{
${ }^{3}$ Our results are robust to a logit model estimation.
} 
strategy.

\subsubsection{Adoption and rejection of the IDD}

As shown in Table 1, there are three states that rejected previously adopted IDD rulings several years after the initial adoption. The IDD dummy in Table 3 captures both the adoptions and subsequent rejections (if any) by each state. Next, we turn to the adoption and rejection effects separately, following Klasa et al. (2017).

To carry out the analysis, we slightly modify Equation (1) by replacing the IDD dummy with an IDD adoption dummy and an IDD rejection dummy. Specifically, we estimate the following model:

$$
I N V E S T_{p}=\beta_{1} \text { Adoption }+\beta_{2} \text { Rejection }+\gamma^{\prime} X+\theta^{\prime} Y+\lambda^{\prime} Z+\tau_{t}+\alpha_{k}+\delta_{j}+\epsilon_{p}
$$

where Adoption is a dummy variable that equals one if firm $i$ in state $j$ has adopted the IDD from year $t$ and zero otherwise. Rejection is a dummy variable that equals one if firm $i$ in state $j$ has rejected IDD from year $t$ and zero otherwise. $\beta_{1}$ and $\beta_{2}$ are the coefficients of interest. They separately demonstrate the effects of IDD adoptions and rejections on VCs' investment likelihood.

\section{[Insert Table 4 Here]}

Columns (1) and (2) in Table 4 present the estimation results. Similar to the baseline results, we observe negative and statistically significant coefficients on the IDD adoption dummies. The regression coefficients are qualitatively similar to those in Table 3 . This observation tells us that adopting the IDD leads to a significant decrease in the likelihood of $\mathrm{VC}$ investment. Rejecting the IDD should have the opposite effect. This is exactly what we observe in Column (1): a positive and statistically significant coefficient on the IDD rejection dummy. However, this coefficient becomes insignificant in Column (2) after more 
control variables are included. This observation is not surprising because the number of states that rejected the IDD is very small (three states).

\subsubsection{Reverse causality}

Even though our host of control variables and fixed effects potentially alleviates concerns in this regard, we carry out formal tests to further ensure that the results we observe are not driven by reverse causality. More specifically, we examine whether it is the states that adopted or rejected the IDD first and hence influenced VCs' investment strategy instead of the other way around. If the changes in VCs' investment strategy or other factors led to the adoption of the IDD, then our results would be invalid. In addition, in a differencein-differences setting, the parallel trends between the treated and control groups must be satisfied.

Following Bertrand and Mullainathan (2003), Giroud and Mueller (2010), and Acharya et al. (2013) among many other researchers utilizing staggered passage of other regulations, we replace the IDD dummy in Equation (1) with seven dummy variables capturing different time points around the adoption of the IDD. We estimate the following form:

$$
\begin{aligned}
\text { INVEST } & =\beta_{1} \text { Adoptionm } 3+\beta_{2} \text { Adoptionm } 2+\beta_{3} \text { Adoptionm } 3+\beta_{4} \text { Adoptionp } 1 \\
& +\beta_{5} \text { Adoptionp } 2+\beta_{6} \text { Adoptionp } 3+\beta_{7} \text { Adoptionp } 4+\beta_{8} \text { rejection } \\
& +\gamma^{\prime} X+\theta^{\prime} Y+\lambda^{\prime} Z+\tau_{t}+\alpha_{k}+\delta_{j}+\epsilon_{p} .
\end{aligned}
$$

We match VC investment dates to IDD ruling dates. We define Adoptionm3, Adoptionm2, Adoptionm1, Adoptionp1, Adoptionp2, Adoptionp3, and Adoptionp4 as dummy variables that equal one if the state adopts IDD in three years, in two years, in one year, during the past year, during the past two years, during the past three years, or four or more years before the date of investment. The rejection dummy is defined the same as in Equation (2). If we 
observe statistically significant coefficients on the Adoptionm3, Adoptionm2, or Adoptionm1 dummies, it means the IDD rulings are determined after the VCs change their investment styles. That is, there is reverse causality.

Column (3) in Table 4 shows no statistically significant coefficients on the Adoptionm3, Adoptionm 2 or Adoptionm1 dummies, which suggests that the parallel trend assumptions are satisfied and our results are not driven by reverse causality. The negative and statistically significant coefficients on Adoptionp4, Adoptionp3, Adoptionp2, and Adoptionp1 are consistent with our baseline results in Table $3 .{ }^{4}$ Note that the rejection effect is again insignificant.

Taking the investment likelihood analyses together, we are able to test the two competing hypotheses- i.e., the Human Capital Risk Hypothesis and the Talent Retention Hypothesis. We formally examine the effects of human capital mobility restrictions on VC investments. Our main results show that, following the adoption of the IDD, there is a drop in the likelihood of VC investment of a meaningful economic magnitude; i.e., IDD reduces VC investment likelihood by $25 \%$. The evidence appears to be consistent with the Human Capital Risk Hypothesis.

\subsection{Investment success}

The ultimate goal for VCs is to earn high returns when they exit the startup companies. As we have argued earlier, the adoption of the IDD deters key talent from leaving a firm and at the same time makes it more difficult for startups to recruit talent. Under the former situation, when firms are able to retain talent, VCs are more likely to exit successfully. In the latter situation, when a firm needs external talent but recruitment from outside is difficult, the resulting suboptimal human capital allocation could hinder startup companies' efficiency

\footnotetext{
${ }^{4}$ Note that one advantage we have in the VC setting is that we can identify the exact dates the VC investments take place and the IDD rulings become effective. Our seven adoption variable captures the true time dynamics of IDD rulings with clear date cutoffs, unlike using financial statement data where the transactions occur over the course of one year, causing some overlapping issues in defining the timing.
} 
and productivity. In those circumstances, VCs are less likely to exit successfully. Overall, how IDD affects VC exits appears to be an empirical question.

To test the effect of the IDD on VC exits, we define IPO and acquisition as two successful exit pathways (e.g., Gompers and Lerner, 2000; Brander et al., 2002; Sørensen, 2007; Bottazzi et al., 2016). The Success dummy equals one if the firm exits by either going public or being acquired by another firm. We next distinguish the two successful exit pathways. The IPO dummy equals one if the firm exits by going public and zero otherwise. For acquisitions, we construct two variables. The Acquisition dummy equals one if the firm exits by being acquired by another firm and zero otherwise. Deal value/amount invested is the M\&A deal value scaled by the total amount invested by VCs. Specifically, we estimate the following equation:

$$
\text { OUTCOME } E_{r}=\beta I D D+\gamma^{\prime} X+\theta^{\prime} Y+\lambda^{\prime} Z+\tau_{t}+\alpha_{k}+\delta_{j}+\epsilon_{p}
$$

The independent variables are the same as those in Equation (1). Unlike the investment likelihood test, we carry out the exit outcome tests with realized VC-startup pairs. Following the standard approach in the VC literature on VC exit, we require the sample to include VC-backed firms that receive first-round funding from 1980 to 2012 . Table 5 presents the results estimating equation (3).

[Insert Table 5 Here]

In Column (1), we use Success as the dependent variable. We find a negative and significant relation between successful exits and the passage of the IDD. The point estimate is $2.98 \%$. This result tells us that VCs' exit probabilities are significantly lower after the adoption of the IDD than before the adoption. Since the Success dummy consists of both IPO deals and M\&A deals, this evidence suggests that overall VCs are less likely to exit successfully.

In Columns (2) through (4), we split success into IPO and acquisition and examine how 
they are affected by the IDD adoption. In Column (2), we report that, after the adoption of the IDD, VCs are $3.4 \%$ less likely to exit through an IPO. Given that the unconditional mean of an IPO is $13.2 \%$, this result is economically sizable, representing a $26 \%$ lower likelihood of exiting through an IPO. In Column (3), we use an acquisition dummy as the dependent variable. Here we find statistically insignificant results. And the point estimate is small. One possible explanation could be that, regardless of whether the IDD exists, VCs' secondbest choice is to exit through acquisition. ${ }^{5}$ Thus the impact of the IDD on the likelihood of acquisition is minimal. ${ }^{6}$

In Column (4), we attempt to capture the impact of the IDD on acquisition by using the M\&A deal value scaled by the total amount invested by VCs as the outcome variable, which is essentially a return on investment (ROI) measure. We find a negative and significant effect of the IDD on M\&A deal value. The lower return on investment (ROI) of approximately 8.39\% is substantial. Considering that the average long-run equity market return is approximately $7 \%$, this loss is significant. It is also worth noting that the unconditional mean of this measure is $33.25 \%$. Our result represents a $25 \%$ lower return after the adoption of the IDD than before the adoption. This economically meaningful result is similar in magnitude to our findings using the IPO dummy as the outcome variable (i.e., 26\%).

In sum, these results suggest that restrictions on startups' human capital mobility could reduce successful exits, providing further support to our Human Capital Risk Hypothesis. The adoption of the IDD causes suboptimal human capital allocation, which might lead to a decline in firms' efficiency and productivity. This reduced productivity potentially contributes to the lower probability of a successful exit by VC. Later on, we find that firms'

\footnotetext{
${ }^{5}$ Chen et al. (2017) find that the adoption of the IDD leads to more human-capital-driven acquisitions among public firms. It is highly likely that some public firms are interested in acquiring startups as a way of also acquiring their talent after the adoption of the IDD. Doing so would increase the startup company's chances of being acquired. The negative effect of the human capital risk channel could be offset by the positive effect of public firms' human capital-driven acquisitions; we therefore find an insignificant effect of IDD on a firm's exit likelihood through acquisition. This might be an alternative explanation.

${ }^{6}$ Our summary statistics reveal that startups are almost four times more likely to exit through an acquisition than through an IPO: $61.9 \%$ of the firms successfully exit either through an IPO $(13.2 \%)$ or an acquisition (48.7\%).
} 
innovation outputs are significantly reduced after the adoption of the IDD, which is consistent with this explanation.

\subsection{Mechanisms}

Our main findings as discussed in previous subsections suggest that the passage of the IDD impedes VC investment and reduces the likelihood that startup companies will exit successfully. If human capital risk created by the adoption of the IDD is the reason, we would expect this negative impact to be more pronounced in human-capital-intensive industries or among firms that are in the greatest need of human capital. Therefore, in this subsection, we explore the human capital risk channel by carrying out tests with our rich cross-sectional data. More precisely, we examine startup companies that require a large fraction of high-skilled workers, are in industries with intensive patenting activity, and are in the early financing stage when concerns about human capital risk are more significant We expect to observe more negative effects of the IDD in these firms.

We estimate both the VC investment likelihood (Equation(1)) and the exit outcome equation (Equation(4)) by including an interaction term to capture the cross-sectional effects. Table 6 presents our estimation results. In Columns (1) to (3), we test the investment likelihood effect using the hypothetical sample of VC-startup pairs from subsection 4.1. The dependent variable is Investment, which is a dummy variable that equals one if the VCstartup deal actually takes place and zero otherwise. In Columns (4) to (6), we test the investment exit effect using the sample of real VC-startup pairs from subsection 4.2. The

dependent variable, Success, is a dummy variable that equals one if the startup exits by either going public or being acquired by another firm and zero otherwise.

\section{[Insert Table 6 Here]}

We start by investigating the startup companies that are in industries with high-skilled 
labor as well as the ones in industries with low-skilled labor and present the results in Columns (1) and (4). Industries with more high-skilled labor tend to be in greater need of talented human capital. The lower human capital mobility after adoption of the IDD should have a more negative impact on those industries. As a result, VCs should be less likely to allocate more resources to those industries. Industries that use primarily low-skilled labor can easily find replacement workers without worrying too much about the consequences of the IDD because low-skilled workers are less likely to possess advanced skills or the firm's technological secrets.

To empirically test this hypothesis, we define a high-skilled-worker dummy that equals one if the firm is in an industry that requires a large fraction of high-skilled labors and zero otherwise. We calculate the high-skilled labor ratio using data from the Integrated Public Use Microdata Series (IPUMS-USA). ${ }^{7}$ We divide the number of skilled workers by total workers in each industry. For firms in the highest quintile of high-skilled-worker industries, we assign the high-skilled-worker dummy a value of one. Similarly, for firms in the lowest quintile of high-skilled-worker industries, we assign the high-skilled-worker dummy a value of zero. We interact the high-skilled-worker dummy variable with the IDD dummy, which equals one if the state adopts the IDD and zero otherwise. The interaction term is the variable of interest. The test results are largely consistent with our hypothesis. The VCs invest more conservatively in firms in industries with high-skilled labors after the adoption of the IDD. Moreover, we find that firms in industries with high-skilled labor are less likely to exit successfully after the adoption of the IDD than are firms in industries with low-skilled labor. These findings confirm the Human Capital Risk Hypothesis.

We next compare startup companies in patent-intensive industries with firms in industries with low patent intensity and show the results in Columns (2) and (5) of Table 6. We calculate industry patenting intensity using all firms in the Compustat database by finding

\footnotetext{
${ }^{7}$ For details, see https://usa.ipums.org/usa/
} 
the average number of patents at the three-digit SIC code level. ${ }^{8}$ We define patent-intensive industries as those with patenting output in the top quintile and low-patent-intensity industries as those with patenting intensity in the bottom quintile. Because startup firms in patent-intensive industries devote more resources to research and development, they are in greater need of talent. The adoption of the IDD should therefore have a larger impact on those startups. We find statistically significant results that are consistent with this prediction. Specifically, firms in patent-intensive industries are less likely to receive VC investments and experience fewer successful exits after the adoption of the IDD than are firms in the low-patent-intensity group.

We then compare firms that receive investments at early stages with those that receive investments at later stages; the results are presented in Columns (3) and (6) of Table 6. Firms that seek VC financing at an early stage need more talented employees to help the development of the venture and thus should be affected more by the human capital risk created by the adoption of the IDD. Therefore we should expect our main findings to be more pronounced among firms that receive $\mathrm{VC}$ financing at early stages. We define an early dummy, which equals one if the firm is in the "startup/seed" or "early stag" as indicated by the VentureXpert database and zero otherwise. We interact the early dummy variable with the IDD dummy, and the interaction term is the variable of interest. Again, the test results are in line with our expectation, as shown by the negative and statistically significant coefficients on the interaction term.

To summarize, the cross-sectional tests show that our main findings are more pronounced in industries that rely more on high-skilled workers, in industries with higher patenting intensity, and in firms with earlier-stage VC investment. These results suggest that human capital risk (in the form of low human capital mobility) is a plausible underlying mechanism affecting VC investment and outcomes. Startup firms with these characteristics tend to

\footnotetext{
${ }^{8}$ The public firm patent data come from Kogan et al. (2017). We thank them for making the data publicly available.
} 
rely more on human capital in their development, and hence restrictions on human capital mobility lead to greater human capital risk.

\subsection{VC investment strategy}

The investment likelihood test in Table 3 shows that VCs become more conservative when making investment decisions after the adoption of the IDD. In this subsection, we explore how VCs alter their investment strategies in response to increased human capital risk created by the IDD. More specifically, we focus on two important aspects of VC investment strategiesi.e., staging and syndication.

Staging, the stepwise disbursement of capital from VCs to startups, is an effective way to mitigate agency problems in VC financing. This is because VCs split funding for startups into multiple financing rounds instead of making a larger lump-sum payment upfront(Gompers, 1995; Tian, 2011). VCs take such caution to reduce investment uncertainty as it keeps entrepreneurs in a "tight leash" (Sahlman, 1990; Gompers, 1995), and hence staging has real option value. Syndication, a striking feature of the VC industry, is co-investment in the same startups by multiple VCs (Lerner, 1994). Similar to syndicated bank loans, syndication allows VCs to share the risk associated with startup companies. In a VC syndicate, the participating VCs can share opinions about the investment and make joint decisions based on their combined knowledge. Therefore, if human capital risk is indeed made higher by the adoption of the IDD, VCs could respond to it by intensifying staging and forming a syndicate.

In our analysis, we estimate a regression specification that is similar to Equation (1) by replacing the outcome variable with VC investment strategy measures. More specifically, we run OLS regressions in the following model:

$$
\text { INVEST STRATEGY }=\beta I D D+\gamma^{\prime} X+\theta^{\prime} Y+\lambda^{\prime} Z+\tau_{t}+\alpha_{k}+\delta_{j}+\epsilon_{p}
$$


We use three variables to gauge VC investment strategy: Number of rounds, Skewness, and Number of VCs. Table 7 presents the estimation results. In Column (1), Number of rounds is the dependent variable. A positive coefficient on IDD would indicate that VCs maintain greater control over the startups by splitting financing into several rounds. We observe a positive and statistically significant coefficient, which suggests that VCs employ a larger number of rounds after the adoption of the IDD, in response to increased human capital risk.

\section{[Insert Table 7 Here]}

In Column (2), Skewness is the dependent variable. Skewness gauges the fraction of total investment that goes toward the first round of venture financing. A positive coefficient would mean that VCs are opening up the hose to pour more money into the startup during the first round, which suggests more aggressive investment behavior. However, a negative coefficient would mean that VCs are more uncertain about the underlying company and hesitate to invest a large sum at the beginning. We find results consistent with the conservative investment style. Specifically, the coefficient estimate on IDD is negative and significant, which suggests that VCs are less comfortable putting more money into a startup company at the beginning of the investment cycle after the adoption of the IDD.

In Column (3), we replace the dependent variable with Number of VCs, which measures the number of VCs co-investing in startup companies. We observe a positive and statistically significant coefficient estimate on IDD. The evidence suggests that VCs are more likely to form a syndicate after a state adopts the IDD in order to reduce investment risk, consistent with our conjecture.

Overall, we find that VCs follow a more conservative investment strategy in order to reduce investment risk after the adoption of the IDD. These findings are consistent with our hypothesis that a decline in human capital mobility after the adoption of the IDD leads to 
suboptimal human capital allocation; as a result, VCs act more conservatively in order to mitigate the human capital risk. ${ }^{9}$

\section{$5 \quad$ Firm Productivity and Human Capital Mobility}

In this section, we examine the impact of the adoption of the IDD on the human capital of startups to provide more evidence in support of our hypothesis and our findings. More specifically, we study changes in startup companies' productivity and inventors' mobility following the IDD adoption.

\subsection{Analysis of startups' innovative output}

Table 5 shows that VCs exhibit poorer investment outcomes after the adoption of the IDD; the probability of a successful exit and an IPO exit are both lower than they are in states without the IDD. One possible explanation is that suboptimal human capital allocation reduces a startup company's productivity after the adoption of the IDD. Thus, in this section, we use patent data to investigate the effect of the IDD on startup companies' innovative output, expanding our sample to all firms that have filed patents with the United States Patent and Trademark Office (USPTO). Specifically, we estimate the following model:

$$
\text { INNOVATIVE OUTPUT } T_{r}=\beta I D D+\gamma^{\prime} X+\theta^{\prime} Y+\lambda^{\prime} Z+\tau_{t}+\alpha_{k}+\delta_{j}+\epsilon_{p},
$$

where we replace the outcome variable in Equation (1) with measures of innovative output. We use two dependent variables to gauge a firm's innovative output: Number of patents and Citation. We define $\operatorname{Ln}($ patent), which is the natural logarithm of one plus total number

\footnotetext{
${ }^{9}$ Intuitively, a longer incubation period tends to lead to more financing rounds. Thus, we also include incubation period as one of the control variables in the estimation. In addition, we use number of rounds scaled by incubation period and incubation period divided by the number of rounds as dependent variables to examine the effect of the adoption of IDD on VCs' investment and find consistent results.
} 
of patents produced by the firm until the exit. We also define Ln(citation), which is the natural logarithm of number of citations per patent of the firm's patents. Table 8 reports the estimation results.

[Insert Table 8 Here]

As shown in Column (1), the coefficient estimate on the IDD dummy is negative and statistically significant This result suggests that firms produce fewer patents after the adoption of the IDD. The lower output is also confirmed by the results reported in Column (2), which suggests that each of a firms' patents generates fewer citations after the adoption of the IDD. Thus our findings show that the adoption of the IDD has a negative impact on a firm's innovative output. This is one potential reason for firms worse exit outcome.

\subsection{Analysis of inventors' mobility}

Several studies of the consequences of the IDD find that, after the adoption of the IDD, employees become more restricted to job hopping activities, especially those with access to important information pertaining to their respective employers. In this subsection, we provide evidence on employees' mobility surrounding the adoption of the IDD. We examine employees' within-state mobility and out-of-state mobility separately. Since the IDD is adopted at the state level, within-state moves are under each state's jurisdiction. Therefore we expect the adoption of the IDD to have a negative effect on inventors' mobility within a state. Intuitively, we would expect inventors who change jobs to move away from states with the IDD in order to avoid lawsuits. Moving to another state, however, raises issues such as moving costs and family relocation. Consequently, we might observe the adoption of the IDD to have a little or no effect on out-of-state moves.

It is difficult to find micro-level datasets that track each employee's employment history. The inventor mobility database maintained by Harvard Business School, however, is a good 
source for our purposes. First, the mobility database tracks the employment changes of all inventors through their patent filings. Second, inventors are the group of people who are most susceptible to the results of the IDD rulings. They have knowledge and are the creators of intellectual properties that relate to their employers' core businesses and bottom lines.

We assemble a dataset at the inventor level for this analysis. Specifically, we obtain the Disambiguation and Co-authorship Networks of the U.S. Patent Inventor Database (19752010) from Harvard University. ${ }^{10}$ We restrict our sample period to 1980-2010 to match the VC sample as closely as possible. We identify an inventor as a "mover" (someone who has moved to a new job) if he or she has two successive patent filings assigned to different firms. We first eliminate all inventors who filed only one patent in our sample period. We keep only one observation for each inventor if he/she has multiple patent filings during the same year. For simplicity, we define the year of the move as the midpoint between the year of the first patent filing and the year of the second patent filing. ${ }^{11}$

\section{[Insert Table 9 Here]}

Table 9 presents our linear probability regression results about the effect of adoption of the IDD on inventor mobility. The sample includes inventors of all patents filed from 1980 to 2010. The dependent variable, Move dummy, equals one if two successive patent filings are assigned to different firms and zero otherwise. In-state move dummy equals one if two successive patent filings are assigned to different firms in the same state and zero otherwise. Out-of-state move dummy equals one if two successive patent filings are assigned to firms in different states and zero otherwise.

As shown in Column (1), the coefficient estimate on the IDD dummy is negative and statistically significant, which suggests that the adoption of the IDD makes it more difficult

\footnotetext{
${ }^{10}$ The database is available at https://dataverse.harvard.edu/dataset.xhtml?persistentId=hdl:1902.1/15705.

${ }^{11}$ We find qualitatively similar results if we assume the inventor moves right after the first patent filing or right before the second patent filing. However, we believe taking the mid-point between two subsequent patent filings is a sensible approach.
} 
for inventors to move. Column (2) further shows that this negative effect is mainly driven by the reduction in within-state moves. We observe that the magnitudes of the coefficient estimates on the IDD dummy are almost the same in Columns (1) and (2), suggesting that within-state moves are the key driver of our results. As expected, Column (3) shows a slightly positive coefficient on the IDD dummy, but it is not statistically significant. These findings suggest that, after the adoption of the IDD, even though it becomes difficult for inventors to switch jobs within the state, the inventors do not move to other states.

In summary, our results from this section provide more direct evidence that Human Capital Risk Hypothesis we propose explains our main findings: the adoption of the IDD impedes VC investment and reduces VCs' successful exit rates. We find a significant reduction in the mobility of startups' inventors with patents following the IDD adoption. In addition, startups' innovation quantity and quality drop. The results suggest that passage of the IDD distorts human capital allocation across startups by reducing human capital mobility, and it leads to a drop in startups' innovative output.

\section{Conclusion}

In this paper, we investigate the importance of human capital mobility in VC investments and outcomes. Specifically, we examine this research question using the plausibly exogenous variation generated by staggered adoption of the inevitable disclosure doctrine (IDD), which causes a decline in human capital mobility. We find evidence to support the Human Capital Risk Hypothesis: The adoption of the IDD leads to distorted human capital allocation and hence to higher human capital risk associated with startup companies.

We find that the adoption of the IDD reduces VCs' investment propensity and rate of successful exit from startups. Moreover, these negative effects are concentrated in industries that rely more heavily on high-skilled workers, in industries with more intensive patenting 
activities, and in firms with earlier-stage $\mathrm{VC}$ investment. These findings suggest that human capital risk is likely an underlying mechanism through which human capital mobility affects VC investment propensity and outcomes. In addition, we find that, to mitigate the adverse effects of the IDD, VCs adopt more conservative investment strategies by engaging in more staged financing of startups. Finally, we show that the adoption of the IDD reduces inventors' mobility, which contributes to a reduction in startups' innovative output. This study sheds new light on the effect of an important but underexplored determinant of VC investmentthe human capital of startup companies. 


\section{References}

Acharya, Viral V., Ramin P. Baghai, and Krishnamurthy V. Subramanian, 2013, Wrongful discharge laws and innovation, Review of Financial Studies 27, 301-346.

Amornsiripanitch, Natee, Paul A. Gompers, and Yuhai Xuan, 2016, More than money: Venture capitalists on boards, Available on SSRN 2586592.

Bertrand, Marianne, and Sendhil Mullainathan, 2003, Enjoying the quiet life? corporate governance and managerial preferences, Journal of Political Economy 111, 1043-1075.

Bottazzi, Laura, Marco Da Rin, and Thomas Hellmann, 2016, The importance of trust for investment: Evidence from venture capital, Review of Financial Studies 29, 2283-2318.

Brander, James A., Raphael Amit, and Werner Antweiler, 2002, Venture-capital syndication: Improved venture selection vs. the value-added hypothesis, Journal of Economics $\&$ Management Strategy 11, 423-452.

Chemmanur, Thomas, Karen Simonyan, and Hassan Tehranian, 2014, The role of management quality in the IPOs of venture-backed entrepreneurial firms, Working Paper .

Chen, Deqiu, Huasheng Gao, and Yujing Ma, 2017, Human capital driven acquisition: Evidence from the inevitable disclosure doctrine, Available on SSRN 2253576 .

Da Rin, Marco, Thomas Hellmann, and Manju Puri, 2013, A survey of venture capital research, Handbook of the Economics of Finance 2, 573-648.

Ewens, Michael, and Matt Marx, 2015, Executive replacement in venture capital-backed startups, Academy of Management Proceedings 2015, 15059.

Giroud, Xavier, and Holger M. Mueller, 2010, Does corporate governance matter in competitive industries?, Journal of Financial Economics 95, 312-331.

Gompers, Paul, and Josh Lerner, 2000, Money chasing deals? the impact of fund inflows on private equity valuation, Journal of Financial Economics 55, 281-325.

Gompers, Paul A., 1992, The structure of venture capital investment, Harvard Business School, Mimeo .

Gompers, Paul A., 1995, Optimal investment, monitoring, and the staging of venture capital, Journal of Finance 50, 1461-1489. 
Gompers, Paul A., Vladimir Mukharlyamov, and Yuhai Xuan, 2016, The cost of friendship, Journal of Financial Economics 119, 626-644.

Hart, Oliver, 1995, Firms, contracts, and financial structure (Clarendon Lectures in Economics. Oxford: Oxford University Press).

Hellmann, Thomas, and Manju Puri, 2000, The interaction between product market and financing strategy: The role of venture capital, Review of Financial Studies 13, 959-984.

Jeffers, Jessica, 2017, The impact of restricting labor mobility on corporate investment and entrepreneurship, University of Chicago Working Paper.

Klasa, Sandy, Hernan Ortiz-Molina, Matthew Serfling, and Shweta Srinivasan, 2017, Protection of trade secrets and capital structure decisions, Journal of Financial Economics forthcoming.

Kogan, Leonid, Dimitris Papanikolaou, Amit Seru, and Noah Stoffman, 2017, Technological innovation, resource allocation, and growth, Quarterly Journal of Economics 132, 665-712.

Lerner, Joshua, 1994, Venture capitalists and the decision to go public, Journal of Financial Economics 35, 293-316.

Ouimet, Paige Parker, and Rebecca Zarutskie, 2016, Acquiring labor, University of North Carolina - Chapel Hill Working Paper.

Sahlman, William A., 1988, Aspects of financial contracting in venture capital, Journal of Applied Corporate Finance 1, 23-36.

Sahlman, William A., 1990, The structure and governance of venture-capital organizations, Journal of Financial Economics 27, 473-521.

Sørensen, Morten, 2007, How smart is smart money? A two-sided matching model of venture capital, The Journal of Finance 62, 2725-2762.

Tian, Xuan, 2011, The causes and consequences of venture capital stage financing, Journal of Financial Economics 101, 132-159.

Tian, Xuan, 2012, The role of venture capital syndication in value creation for entrepreneurial firms, Review of Finance 16, 245-2836.

Zingales, Luigi, 2000, In search of new foundations, Journal of Finance 55, 1623-1653. 
Table 1

List of the adoption and rejection dates of the IDD

This table presents the adoption and rejection dates of the IDD. Column (1) presents the date on which the IDD is adopted and Column (2) presents the date on which the IDD is rejected by each state.

\begin{tabular}{lcc}
\hline & $(1)$ & $(2)$ \\
State & Adoption Date & Rejection Date \\
\hline Arkansas & March 18, 1997 & \\
Connecticut & February 28, 1996 & \\
Delaware & May 5, 1964 & May 21, 2001 \\
Florida & July 11, 1960 & \\
Georgia & June 29, 1998 & \\
Illinois & February 9, 1989 & \\
Indiana & July 12, 1985 & \\
Iowa & April 1, 1996 & \\
Kansas & February 2, 2006 & \\
Massachusetts & October 13, 1994 2002 \\
Michigan & February 17, 1966 & \\
Minnesota & October 10, 1986 & \\
Missouri & November 2, 2000 & \\
New Jersey & April 27, 1987 & \\
New York & December 5, 1919 & \\
North Carolina & June 17, 1976 & \\
Ohio & September 29, 2000 & \\
Pennsylvania & February 19, 1982 2003 \\
Texas & May 28, 1993 \\
Utah & January 30, 1998 & \\
Washington & December 30, 1997 & \\
\hline
\end{tabular}




\section{Table 2}

\section{Variable definitions and summary statistics}

This table presents variable definitions and summary statistics of the sample used in the analysis. The sample includes VC backed firms from 1980 to 2016. Utility and financial services industries are excluded from the sample. Investment is a dummy variable that equals one if the VC-firm deal actually takes place and zero otherwise. $I D D$ is a dummy variable that equals one if the state adopts the IDD and zero otherwise. VC market share is the venture capitalist's (VCist's) market share in the same MSA at time of investment. $V C$ reputation is the VCist's cumulative IPO market share. Firm ageis the number of years since the venture inception year. Early dummy equals one if the firm is in the "startup/seed" or "early stage" as indicated by the VentureXerpt database and zero otherwise. Distance is the natural logarithm of the distance between firm and VC. Industry fit is the percentage of deals made by the VCist in the same industry. Success is a dummy variable that equals one if the firm exits through either IPO or M\&A and zero otherwise. $I P O$ dummy equals one if the venture goes public and zero otherwise. Acquisition dummy equals one if the venture is involved in a merger or acquisition and zero otherwise. Number of rounds is the total rounds of financing for each venture. Number of VCs is the total number of VCs involved in each deal. Skewness is the fraction of the first-round investment amount over total investment in the same underlying venture. Number of patents is the total number of patents produced by the firm until exit. Citation is the total number of citations of the firm's patents until exit. Column (1) reports the sample size N; Column (2) reports the sample mean. Column (3) reports the sample standard deviation. Column (4) reports the sample 25th percentile. Column (5) reports the sample 50th percentile. Column (6) reports the sample 75 th percentile. 
Table 2

Variable definitions and summary statistics

\begin{tabular}{|c|c|c|c|c|c|c|}
\hline Variables & \multicolumn{6}{|c|}{ Description } \\
\hline Investment & \multicolumn{6}{|c|}{$=1$ if the VC-firm deal actually takes place } \\
\hline IDD & \multicolumn{6}{|c|}{$=1$ if the state passes the IDD } \\
\hline VC market share & \multicolumn{6}{|c|}{ VCist's market share in the same MSA at time of investment } \\
\hline VC reputation & \multicolumn{6}{|c|}{ VCist's cumulative IPO market share. } \\
\hline Firm age & \multicolumn{6}{|c|}{ number of years since the venture inception year } \\
\hline Early dummy & \multicolumn{6}{|c|}{$=1$ if the firm is in the "startup/seed" or "early stage" } \\
\hline Distance & \multicolumn{6}{|c|}{ natural logarithm of the distance between firm and VC } \\
\hline Industry fit & \multicolumn{6}{|c|}{ percentage of deals made by the VCist in the same industry } \\
\hline Success & \multicolumn{6}{|c|}{$=1$ if the firm exits through either IPO or M\&A } \\
\hline IPO & \multicolumn{6}{|c|}{$=1$ if the venture goes public } \\
\hline Acquisition & \multicolumn{6}{|c|}{$=1$ if the venture is involved in a merger or acquisition } \\
\hline deal value/amount invested & \multirow{2}{*}{\multicolumn{6}{|c|}{$\begin{array}{l}\text { the M\&A deal value scaled by the total amount invested by VCs } \\
\text { total number of financing rounds in each venture }\end{array}$}} \\
\hline Number of rounds & & & & & & \\
\hline Number of VCs & \multicolumn{6}{|c|}{ total number of VCs involved in each deal } \\
\hline Skewness & \multirow{2}{*}{\multicolumn{6}{|c|}{ first round investment amount over total investment amount }} \\
\hline Number of patents & & & & & & \\
\hline Citation & \multicolumn{6}{|c|}{$\begin{array}{l}\text { total number of patents produced by the nrm until exit } \\
\text { total number of citations of the firm's patents until exit }\end{array}$} \\
\hline & $(1)$ & $(2)$ & $(3)$ & (4) & $(5)$ & (6) \\
\hline Variables & $\mathrm{N}$ & Mean & Std.Dev & $\mathrm{P} 25$ & $\mathrm{P} 50$ & P75 \\
\hline Investment & 374,180 & 0.1280 & 0.3340 & 0 & 0 & 0 \\
\hline IDD & 374,180 & 0.3873 & 0.4871 & 0 & 0 & 1 \\
\hline VC market share & 374,180 & 0.0091 & 0.0404 & 0.0009 & 0.0024 & 0.0061 \\
\hline VC reputation & 374,180 & 0.0026 & 0.0036 & 0.0003 & 0.0012 & 0.0034 \\
\hline Firm age & 374,180 & 4.5740 & 7.0821 & 1 & 2 & 5 \\
\hline Early dummy & 374,180 & 0.6937 & 0.4609 & 0 & 1 & 1 \\
\hline Distance & 374,180 & 6.3485 & 1.8864 & 5.8278 & 7.1170 & 7.7834 \\
\hline Industry fit & 374,180 & 0.4236 & 0.3029 & 0.1429 & 0.3966 & 0.6667 \\
\hline Success & 15,335 & 0.6192 & 0.4856 & 0 & 0 & 1 \\
\hline IPO & 15,335 & 0.1321 & 0.3386 & 0 & 0 & 0 \\
\hline Acquisition & 15,335 & 0.4871 & 0.4998 & 0 & 0 & 1 \\
\hline Deal value/amount invested & 13,118 & 0.3325 & 1.6350 & 0 & 0 & 0 \\
\hline Number of rounds & 15,335 & 3.9347 & 3.0043 & 1 & 3 & 5 \\
\hline Number of VCs & 15,335 & 11.4743 & 12.2901 & 3 & 7 & 16 \\
\hline Skewness & 12,153 & 0.4314 & 0.3872 & 0.0832 & 0.2691 & 0.9374 \\
\hline Number of patents & 15,335 & 1.4595 & 5.0815 & 0 & 0 & 0 \\
\hline Citations & 15,335 & 2.4362 & 8.3770 & 0 & 0 & 0 \\
\hline
\end{tabular}




\section{Table 3}

\section{Likelihood of VC investment}

This table presents OLS regression results of the effect of IDD rulings on VCs' investment likelihood. The sample includes all possible VC-firm pairs from 1980 to 2016 . We require the VC to be in existence before the firm and to invest in the same industry as the firm in the next 30 days. Utility and financial services industries are excluded from the sample. The dependent variable is Investment, which is a dummy variable that equals one if the VC-firm deal pair actually takes place and zero otherwise. $I D D$ is the key independent variable that equals one if the state adopts the IDD and zero otherwise. The control variables are defined as follows: VC market share is the VCist's market share in the same MSA at the time of investment; VC reputation is the VCist's cumulative IPO market share; Ln(age) is the natural logarithm of number of years since the venture inception year; Early dummy equals one if the firm is in the "startup/seed" or "early stage" as indicated by the VentureXerpt database and zero otherwise; Distance is the natural logarithm of the distance between firm and VC; Industry fit is the percentage of deals made by the VCist in the same industry. All continuous variables are winsorized at the $1 \%$ and $99 \%$ levels. Robust standard errors clustered at the lead VC level are reported in parentheses. ***, **, and * indicate significance at the $1 \%, 5 \%$, and $10 \%$ levels, respectively.

\begin{tabular}{lccc}
\hline & $(1)$ & $(2)$ & $(3)$ \\
VARIABLES & Investment & Investment & Investment \\
\hline IDD & $-0.0319^{* * *}$ & $-0.0316^{* * *}$ & $-0.0324^{* * *}$ \\
VC market share & $(0.0047)$ & $(0.0065)$ & $(0.0062)$ \\
& & & 0.0416 \\
VC reputation & & $(0.0253)$ \\
& & & $0.0052^{* * *}$ \\
Ln(age) & & $(0.0009)$ \\
& & & $-0.0067^{* * *}$ \\
Early dummy & & & $(0.0015)$ \\
& & & $0.0068^{* *}$ \\
Distance & & & $(0.0028)$ \\
& & & $-0.0197^{* * *}$ \\
Industry fit & & & $(0.0008)$ \\
& & & -0.0047 \\
Industry FE & $\mathrm{N}$ & $\mathrm{Y}$ & $(0.0040)$ \\
Year FE & $\mathrm{N}$ & $\mathrm{Y}$ & $\mathrm{Y}$ \\
MSA FE & 374,180 & $\mathrm{Y}$ & $\mathrm{Y}$ \\
Observations & 0.0020 & 374,161 & $\mathrm{Y}$ \\
R-squared & & 0.2694 & 374,161 \\
\hline
\end{tabular}




\section{Table 4}

\section{Effects of IDD adoption and rejection}

This table presents OLS regression results of the effect of IDD rulings on VCs' investment likelihood. The sample includes all possible VC-firm pairs from 1980 to 2016 . We require the VC to be in existence before the firm and to invest in the same industry as the firm in the next 30 days. Utility and financial services industries are excluded from the sample. The dependent variable is Investment, which is a dummy variable that equals one if the VC-firm deal pair actually takes place and zero otherwise. In Columns (1) and (2), IDD adoption and IDD rejection are the key independent variables that equal one if the state adopts or rejects IDD, respectively, and zero otherwise. In Column (3), IDD adoptionm3, IDD adoptionm2, IDD adoptionm 1 , IDD adoptionp1, IDD adoptionp 2 , IDD adoptionp3, and IDD adoptionp4 are dummy variables that equal one if the state adopts the IDD in three years, in two years, in one year, during the past year, during the past two years, during the past three years, and four or more years before the date of investment, respectively and $I D D$ rejection is a dummy variable that equals one if the state rejects the IDD. The control variables are defined as follows: $V C$ market share is the VCist's market share in the same MSA at the time of investment; VC reputation is the VCist's cumulative IPO market share; $\operatorname{Ln}($ age $)$ is the natural logarithm of number of years since the venture inception year; Early dummy equals one if the firm is in the "startup/seed" or "early stage" as indicated by the VentureXerpt database and zero otherwise; Distance is the natural logarithm of the distance between firm and VC; Industry fit is the percentage of deals made by the VCist in the same industry. All continuous variables are winsorized at the $1 \%$ and $99 \%$ levels. Robust standard errors clustered at the lead $\mathrm{VC}$ level are reported in parentheses. ${ }^{* * *},{ }^{* *}$, and $*$ indicate significance at the $1 \%, 5 \%$, and $10 \%$ levels, respectively. 
Table 4

Effects of IDD adoption and rejection

\begin{tabular}{|c|c|c|c|}
\hline VARIABLES & $\begin{array}{c}(1) \\
\text { Investment }\end{array}$ & $\begin{array}{c}(2) \\
\text { Investment }\end{array}$ & $\begin{array}{c}(3) \\
\text { Investment }\end{array}$ \\
\hline Adoption & $\begin{array}{c}-0.0332^{* * *} \\
(0.0049)\end{array}$ & $\begin{array}{c}-0.0533^{* * *} \\
(0.0080)\end{array}$ & \\
\hline IDD adoptionm3 & & & $\begin{array}{l}-0.0156 \\
(0.0252)\end{array}$ \\
\hline IDD adoptionm2 & & & $\begin{array}{l}-0.0058 \\
(0.0198)\end{array}$ \\
\hline IDD adoptionm1 & & & $\begin{array}{l}-0.0162 \\
(0.0155)\end{array}$ \\
\hline IDD adoptionp1 & & & $\begin{array}{c}-0.0368^{* * *} \\
(0.0135)\end{array}$ \\
\hline IDD adoptionp2 & & & $\begin{array}{c}-0.0628^{* * *} \\
(0.0120)\end{array}$ \\
\hline IDD adoptionp3 & & & $\begin{array}{c}-0.0484^{* * *} \\
(0.0123)\end{array}$ \\
\hline IDD adoptionp4 & & & $\begin{array}{c}-0.0635^{* * *} \\
(0.0110)\end{array}$ \\
\hline IDD rejection & $\begin{array}{c}0.0331^{* * *} \\
(0.0111)\end{array}$ & $\begin{array}{l}-0.0062 \\
(0.0067)\end{array}$ & $\begin{array}{l}-0.0047 \\
(0.0067)\end{array}$ \\
\hline VC market share & & $\begin{array}{c}0.0402 \\
(0.0253)\end{array}$ & $\begin{array}{c}0.0400 \\
(0.0253)\end{array}$ \\
\hline VC reputation & & $\begin{array}{c}0.0049 * * * \\
(0.0009)\end{array}$ & $\begin{array}{c}0.0049^{* * *} \\
(0.0010)\end{array}$ \\
\hline Ln(age) & & $\begin{array}{c}-0.0062^{* * *} \\
(0.0015)\end{array}$ & $\begin{array}{c}-0.0061^{* * *} \\
(0.0015)\end{array}$ \\
\hline Early dummy & & $\begin{array}{c}0.0064^{* *} \\
(0.0028)\end{array}$ & $\begin{array}{c}0.0064^{* *} \\
(0.0028)\end{array}$ \\
\hline Distance & & $\begin{array}{c}-0.0197^{* * *} \\
(0.0008)\end{array}$ & $\begin{array}{c}-0.0197^{* * *} \\
(0.0008)\end{array}$ \\
\hline Industry fit & & $\begin{array}{l}-0.0047 \\
(0.0040)\end{array}$ & $\begin{array}{l}-0.0046 \\
(0.0040)\end{array}$ \\
\hline Industry FE & $\mathrm{N}$ & $\mathrm{Y}$ & $\mathrm{Y}$ \\
\hline Year FE & $\mathrm{N}$ & $\mathrm{Y}$ & $\mathrm{Y}$ \\
\hline MSA FE & $\mathrm{N}$ & $\mathrm{Y}$ & $\mathrm{Y}$ \\
\hline Observations & 374,180 & 374,161 & 374,161 \\
\hline R-squared & 0.0022 & 0.2811 & 0.2813 \\
\hline
\end{tabular}




\section{Table 5}

\section{Effect of the adoption of the IDD on VC exit outcomes}

This table presents OLS regression results on the effect of the IDD rulings on VCist exit outcomes. The sample includes VC backed firms from 1980 to 2012. Utility and financial services industries are excluded from the sample. In Column (1), the dependent variable success is a dummy variable that equals one if the firm exits by going public or being acquired by another firm and zero otherwise. In Column (2), the dependent variable IPO is a dummy variable that equals one if the venture goes public and zero otherwise. In Column (3), the dependent variable acquisition is a dummy variable that equals one if the venture is involved in a merger or acquisition and zero otherwise. In Column (4), the dependent variable deal value/amountinvested is the M\&A deal value scaled by the total amount invested by VCs. IDD is the key independent variable that equals one if the state adopts the IDD and zero otherwise. The control variables are defined as follows: $V C$ market share is the VCist's market share in the same MSA at time of investment; VC reputation is the VCist's cumulative IPO market share; Ln(age) is the natural logarithm of number of years since the venture inception year; Early dummy equals one if the firm is in the "startup/seed" or "early stage" as indicated by the VentureXerpt database and zero otherwise; Distance is the natural logarithm of the distance between firm and VC; Industry fit is the percentage of deals made by the VCist in the same industry. All continuous variables are winsorized at the $1 \%$ and $99 \%$ levels. Robust

standard errors clustered at the lead VC level are reported in parentheses. ${ }^{* * *}$, ${ }^{* *}$, and $*$ indicate significance at the $1 \%, 5 \%$, and $10 \%$ levels, respectively. 
Table 5

Effect of the adoption of the IDD on VC exit outcomes

\begin{tabular}{|c|c|c|c|c|}
\hline VARIABLES & Success & IPO & Acquisition & $\begin{array}{c}(4) \\
\text { Deal value/ } \\
\text { amount invested }\end{array}$ \\
\hline IDD & $\begin{array}{c}-0.0298^{* *} \\
(0.0142)\end{array}$ & $\begin{array}{c}-0.0342^{* * *} \\
(0.0102)\end{array}$ & $\begin{array}{c}0.0044 \\
(0.0146)\end{array}$ & $\begin{array}{l}-0.0839^{*} \\
(0.0501)\end{array}$ \\
\hline VC market share & $\begin{array}{c}0.0059 \\
(0.0317)\end{array}$ & $\begin{array}{c}0.0031 \\
(0.0226)\end{array}$ & $\begin{array}{c}0.0028 \\
(0.0312)\end{array}$ & $\begin{array}{l}-0.1129 \\
(0.0896)\end{array}$ \\
\hline VC reputation & $\begin{array}{c}0.0125^{* * *} \\
(0.0030)\end{array}$ & $\begin{array}{c}0.0118^{* * *} \\
(0.0023)\end{array}$ & $\begin{array}{c}0.0007 \\
(0.0031)\end{array}$ & $\begin{array}{c}0.0091 \\
(0.0104)\end{array}$ \\
\hline Ln(age) & $\begin{array}{c}0.0223^{* * *} \\
(0.0040)\end{array}$ & $\begin{array}{l}-0.0034 \\
(0.0030)\end{array}$ & $\begin{array}{c}0.0257^{* * *} \\
(0.0043)\end{array}$ & $\begin{array}{c}0.0421^{* *} \\
(0.0165)\end{array}$ \\
\hline Early dummy & $\begin{array}{c}-0.0608^{* * *} \\
(0.0100)\end{array}$ & $\begin{array}{c}-0.0221^{* * *} \\
(0.0080)\end{array}$ & $\begin{array}{c}-0.0388^{* * *} \\
(0.0104)\end{array}$ & $\begin{array}{l}-0.0533 \\
(0.0396)\end{array}$ \\
\hline Distance & $\begin{array}{c}0.0026 \\
(0.0023)\end{array}$ & $\begin{array}{c}0.0036^{* *} \\
(0.0017)\end{array}$ & $\begin{array}{l}-0.0010 \\
(0.0022)\end{array}$ & $\begin{array}{l}-0.0037 \\
(0.0075)\end{array}$ \\
\hline Industry fit & $\begin{array}{l}-0.0270 \\
(0.0249)\end{array}$ & $\begin{array}{c}0.0264 \\
(0.0216)\end{array}$ & $\begin{array}{c}-0.0534^{* *} \\
(0.0270)\end{array}$ & $\begin{array}{c}0.0779 \\
(0.0965)\end{array}$ \\
\hline Industry FE & $\mathrm{Y}$ & $\mathrm{Y}$ & $\mathrm{Y}$ & $\mathrm{Y}$ \\
\hline Year FE & $\mathrm{Y}$ & $\mathrm{Y}$ & $\mathrm{Y}$ & $\mathrm{Y}$ \\
\hline MSA FE & $\mathrm{Y}$ & $\mathrm{Y}$ & $\mathrm{Y}$ & $\mathrm{Y}$ \\
\hline Observations & 15,286 & 15,286 & 15,286 & 13,067 \\
\hline R-squared & 0.0989 & 0.1167 & 0.0990 & 0.0508 \\
\hline
\end{tabular}




\section{Table 6}

\section{Cross-sectional test results}

This table presents cross-sectional OLS regression results about the effect of the IDD rulings on VCs' investment likelihood and exit outcomes. The test carried out here are similar to those in Tables 3 and 5. In Columns (1) to (3), the sample includes all possible VC-firm pairs from 1980 to 2016. We require the $\mathrm{VC}$ to be in existence before the firm and to invest in the same industry as the firm in the next 30 days. The dependent variable is Investment, which is a dummy variable that equals one if the VC-firm deal actually takes place and zero otherwise. In Columns (4) to (6), the sample includes VC backed firms from 1980 to 2012 and success is the dependent variable, which is a dummy variable that equals one if the firm exits by going public or being acquired by another firm and zero otherwise. Utility and financial services industries are excluded from the sample. We calculate the high-skilled labor ratio using data from IPUMS-USA. We divide the number of skilled workers by total workers in each industry. For firms in the highest quintile of high-skilled-worker industries, we assign the high-skilled-worker dummy a value of one. Similarly, for firms in the lowest quintile of high-skilled-worker industries, we assign the high-skilled-worker dummy a value of zero. We calculate industry patenting intensity from Compustat firms by finding the average number of patents at the three-digit SIC code level. We assign industry patenting intensity dummy a value of one for those with patent output in the top quintile and a value of zero for industries with patenting intensity in the bottom quintile. We also define early dummy, which is a dummy variable that equals one if the firm is in the "startup/seed" or "early stage" as indicated by the VentureXerpt database and zero otherwise. We interact those three dummy variables with the IDD dummy, which equals one if the state adopts the IDD and zero otherwise. The interaction terms are the variables of interest. The control variables are $V C$ market share, $V C$ reputation, $L n($ age), Early dummy, Distance, and Industry fit. All continuous variables are winsorized at the $1 \%$ and $99 \%$ levels. Robust standard errors clustered at the lead VC level are reported in parentheses. $* * *, * *$, and $*$ indicate significance at the $1 \%, 5 \%$, and $10 \%$ levels, respectively. 


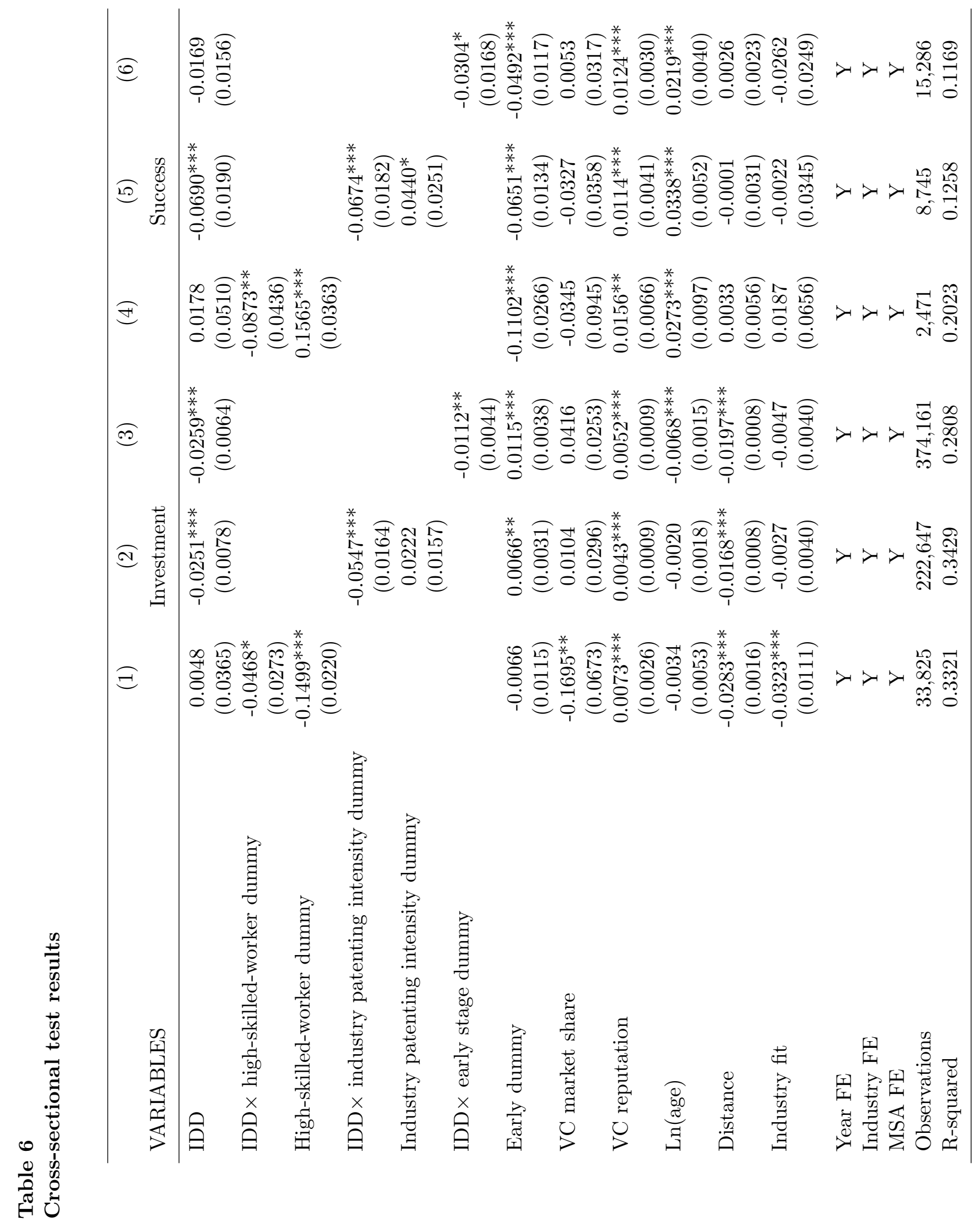




\section{Table 7}

\section{Effect of the adoption of the IDD on VC investment structure}

This table presents OLS regression results of the effect of the IDD rulings on VCs' investment structure. The sample includes VC backed firms from 1980 to 2016. Utility and financial services industries are excluded from the sample. The dependent variables are Number of rounds (Column (1)), Skewness (Column (2)), and Number of VCs (Column (3)). Number of rounds is the natural logarithm of total number of financing rounds in each venture. Number of $V C s$ is the natural logarithm of total number of VCs involved in each deal. Skewness is the fraction of first round investment over total investment in the same underlying venture. IDD is the key independent variable that equals one if the state adopts the IDD and zero otherwise. The control variables are defined as follows: Incubation period is the amount of time from first VC investment to last VC investment; $V C$ market share is the VCist's market share in the same MSA at time of investment; $V C$ reputation is the VCist's cumulative IPO market share; Ln(age) is the natural logarithm of number of years since the venture inception year; Early dummy equals one if the firm is in the "startup/seed" or "early stage" as indicated by the VentureXerpt database and zero otherwise; Distance is the natural logarithm of the distance between firm and VC; Industry fit is the percentage of deals made by the VCist in the same industry. All continuous variables are winsorized at the $1 \%$ and $99 \%$ levels. Robust standard errors clustered at the lead VC level are reported in parentheses. ${ }^{* * *},{ }^{* *}$, and $*$ indicate significance at the $1 \%, 5 \%$, and $10 \%$ levels, respectively.

\begin{tabular}{lccc}
\hline & $(1)$ & $(2)$ & $(3)$ \\
VARIABLES & Number of rounds & Skewness & Number of VCs \\
\hline IDD & $0.0467^{* * *}$ & $-0.0210^{* *}$ & $0.0535^{* *}$ \\
& $(0.0148)$ & $(0.0105)$ & $(0.0245)$ \\
Incubation period & $0.386^{* * *}$ & $-0.115^{* * *}$ & $0.330^{* * *}$ \\
VC market share & $(0.0073)$ & $(0.0037)$ & $(0.0079)$ \\
& 0.0131 & 0.0033 & $-0.1570^{* *}$ \\
VC reputation & $(0.0336)$ & $(0.0250)$ & $(0.0622)$ \\
& $0.0102^{* *}$ & -0.0036 & $0.0405^{* * *}$ \\
Ln(age) & $(0.0045)$ & $(0.0025)$ & $(0.0073)$ \\
& $-0.0603^{* * *}$ & $0.0631^{* * *}$ & $-0.0768^{* * *}$ \\
Early dummy & $(0.0045)$ & $(0.0039)$ & $(0.0074)$ \\
Distance & $0.1510^{* * *}$ & $-0.1270^{* * *}$ & $0.2720^{* * *}$ \\
& $(0.0117)$ & $(0.0078)$ & $(0.0197)$ \\
Industry fit & $-0.0053^{* *}$ & 0.0005 & 0.0010 \\
& $(0.0023)$ & $(0.0012)$ & $0.0037)$ \\
Industry FE & -0.0034 & $-0.0481^{* * *}$ & 0.0658 \\
Year FE & $(0.0259)$ & $(0.0162)$ & $(0.0406)$ \\
MSA FE & $\mathrm{Y}$ & $\mathrm{Y}$ & $\mathrm{Y}$ \\
Observations & $\mathrm{Y}$ & $\mathrm{Y}$ & $\mathrm{Y}$ \\
R-squared & 12,219 & $\mathrm{Y}$ & 12,219 \\
\hline
\end{tabular}




\section{Table 8}

\section{Effect of the adoption of the IDD on firms' innovative output}

This table presents OLS regression results of the effect of the IDD rulings on startup companies' innovative output. The sample includes VC backed firms from 1980 to 2016. Utility and financial services industries are excluded from the sample. In Column (1), the dependent variable is Ln(patent), which is the natural logarithm of the total number of patents produced by the firm until exit. In Column (2), the dependent variable is $L n$ (citation), which is the natural logarithm of the number of citations per patent on the firm's patents until exit. IDD is the key independent variable that equals one if the state adopts IDD and zero otherwise. The control variables are defined as follows: VC market share is the VCist's market share in the same MSA at time of investment; VC reputation is VCist's cumulative IPO market share; Ln(age) is the natural logarithm of number of years since the venture inception year; Early dummy equals one if the firm is in the "startup/seed" or "early stage" as indicated by the VentureXerpt database and zero otherwise; Distance is the natural logarithm of the distance between firm and VC; Industry fit is the percentage of deals made by the VCist in the same industry. All continuous variables are winsorized at the $1 \%$ and $99 \%$ levels. Robust standard errors clustered at the lead VC level are reported in parentheses. ${ }^{* * *},{ }^{* *}$, and ${ }^{*}$ indicate significance at the $1 \%, 5 \%$, and $10 \%$ levels, respectively.

\begin{tabular}{lcc}
\hline & $(1)$ & $(2)$ \\
VARIABLES & Ln(patent) & Ln(citation) \\
\hline IDD & $-0.0494^{* *}$ & $-0.1204^{* * *}$ \\
VC market share & $(0.0225)$ & $(0.0283)$ \\
VC reputation & 0.0128 & 0.0121 \\
& $(0.0489)$ & $(0.0528)$ \\
Ln(age) & $0.0230^{* * *}$ & $0.0227^{* * *}$ \\
& $(0.0045)$ & $(0.0054)$ \\
Early dummy & 0.0099 & $0.0257^{* * *}$ \\
& $(0.0069)$ & $(0.0080)$ \\
Distance & $0.0421^{* * *}$ & $0.0803^{* * *}$ \\
& $(0.0146)$ & $(0.0198)$ \\
Industry fit & 0.0024 & 0.0065 \\
& $(0.0032)$ & $(0.0042)$ \\
Industry FE & -0.0214 & 0.0129 \\
Year FE & $(0.0404)$ & $(0.0470)$ \\
MSA FE & $\mathrm{Y}$ & $\mathrm{Y}$ \\
Observations & $\mathrm{Y}$ & $\mathrm{Y}$ \\
R-squared & $\mathrm{Y}$ & $\mathrm{Y}$ \\
\hline
\end{tabular}




\section{Table 9}

\section{Effect of the adoption of the IDD on inventors' mobility}

This table presents OLS regression results of the effect of the IDD rulings on inventors' mobility. The sample includes inventors of all patents filed from 1980 to 2010. In Column (1), the dependent variable, Move, equals one if two successive patent filings are assigned to different firms and zero otherwise. In Columns (2) and (3), we further divide move into in-state move and out-of-state move. IDD is the key independent variable that equals one if the state adopts IDD and zero otherwise. The control variables are defined as follows: Unemployment is the unemployment rate of each state; GDP growth is the growth rate of each state's GDP; Political balance is defined as the fraction of a state's representatives in the U.S. House of Representatives that belong to the Democratic Party. All continuous variables are winsorized at the $1 \%$ and $99 \%$ levels. Robust standard errors clustered at the state level are reported in parentheses. ***, **, and * indicate significance at the $1 \%, 5 \%$, and $10 \%$ levels, respectively.

\begin{tabular}{lccc}
\hline VARIABLES & $(1)$ & $(2)$ & $(3)$ \\
Move & In-state move & Out-of-state move \\
\hline IDD & $-0.0060^{*}$ & $-0.0060^{*}$ & $2.22 e^{-5}$ \\
Unemployment & $(0.0034)$ & $(0.0035)$ & $(0.0004)$ \\
& $3.82 e^{-5}$ & 0.0001 & $-7.57 e^{-5}$ \\
GDP growth & $(0.0007)$ & $(0.0007)$ & $(0.0001)$ \\
& -0.0372 & -0.0393 & 0.0021 \\
Political balance & $(0.0289)$ & $(0.0294)$ & $(0.0032)$ \\
& -0.0030 & -0.0009 & $-0.0020^{*}$ \\
Year FE & $(0.0089)$ & $(0.0087)$ & $(0.0011)$ \\
MSA FE & $\mathrm{Y}$ & $\mathrm{Y}$ & $\mathrm{Y}$ \\
Observations & $\mathrm{Y}$ & $\mathrm{Y}$ & $2,257,717$ \\
R-squared & $2,257,717$ & $2,257,717$ & 0.0024 \\
\hline
\end{tabular}

